\title{
Exploring novel ice-core proxies for paleoclimate reconstruction in the sub-Antarctic
}

\author{
Amy C.F. King ${ }^{1}$ and Dieter R. Tetzner ${ }^{1,2}$
}

\begin{abstract}
New ice-core records are being developed from the sub-Antarctic, a region previously lacking in paleoclimate archives. These records capture marine-sourced organic compounds that act as proxies for sea-ice concentration, and wind-lofted diatoms that reflect westerly wind strength.
\end{abstract}

The sub-Antarctic region is critical to our understanding of past changes in westerly wind strength, sea-ice extent, Southern Ocean biogeochemical cycling, and processes interfacing polar and mid-latitude climate. Yet this region, defined here as southward of the Southern Ocean polar front, is severely lacking in paleoclimate archives. Consequently, our ability to predict future changes in these processes is limited. To answer the need for new climate records, the 2016-2017 Antarctic Circumnavigation Expedition (https://spi-ace-expedition.ch/) collected a suite of shallow (12-24 m depth) ice cores from ice-capped islands and glaciers throughout the Antarctic and sub-Antarctic (Fig. 1). The cores are climate archives for the late 20th century to present day (Thomas et al. 2020). Due to the logistical challenges of accessing such remote islands, several of these cores are the first to have ever been drilled at these sites.

The main objective of the sub-Antarctic icecore drilling expedition is to "plug the gap" by providing paleoclimate records from the data-sparse sub-Antarctic. The PAGES2k Consortium (2017) highlighted the absence of paleoclimate archives across the Southern Ocean. Their global composite database of 692 temperature-sensitive records from 648 locations provides no spatial coverage in the sub-Antarctic. Improving spatial fidelity of records is another project goal. Ice-core reconstructions of marine-sourced components so far rely on cores from coastal Antarctica. Source regions of marine compounds found in these cores may cover entire ocean sectors (shown in Fig. 1). This means local-scale past climatic changes are not captured.

Alongside the collection of new cores has been the development of a number of novel ice-core proxies, focussing on emissions from the marine biosphere. Sub-Antarctic islands are in areas of marine productivity, therefore sub-Antarctic cores ideally lend themselves to marine-sourced proxies. This article highlights the exciting potential of these new proxies for sea-ice concentration and westerly wind strength, both key drivers in global climate dynamics.

\section{Diatoms as proxies for westerly winds} Diatoms are unicellular algae with siliceous cell walls, found in surface waters worldwide. They are especially abundant in major oceanic water-mass convergence zones, such as the Southern Ocean, where nutrient upwelling leads to high productivity. Diatoms are lifted from the ocean surface into the atmosphere by wind-induced bubble-bursting and wave-breaking processes (Cipriano and Blanchard 1981; Farmer et al. 1993). Once in the atmosphere, they can be transported by strong winds over long distances. In polar regions, airborne diatoms are deposited over ice sheets and ice caps, and incorporated into the ice-core record (Budgeon et al. 2012).

Marine and non-marine diatoms have been found in ice cores from several locations across Antarctica (Kellogg and Kellogg 2005). Diatoms are found throughout the Southern Ocean, but Pike et al. (2008) observed the largest blooms occurred during spring near the Antarctic Polar Front zone, the sea-ice margin, or both. In light of this, Allen et al. (2020) and Tetzner et al. (2021) explored the abundance and diversity of diatoms preserved in Antarctic ice cores, highlighting their potential as proxies of wind strength and atmospheric circulation in the Southern Ocean.

The Peter 1st and Bouvet ice cores (providing climate records for 1999-2017 and 2001 2017, respectively) were obtained from two strategic locations to track changes in the westerly wind belt. Preliminary results from Tetzner et al. (2021), indicate that the Peter 1 st ice-core diatom record presents correlations with winds in several locations; a positive correlation $(R>0.8, p<5 \%)$ with ERA5reanalysis wind strength in the westerly wind

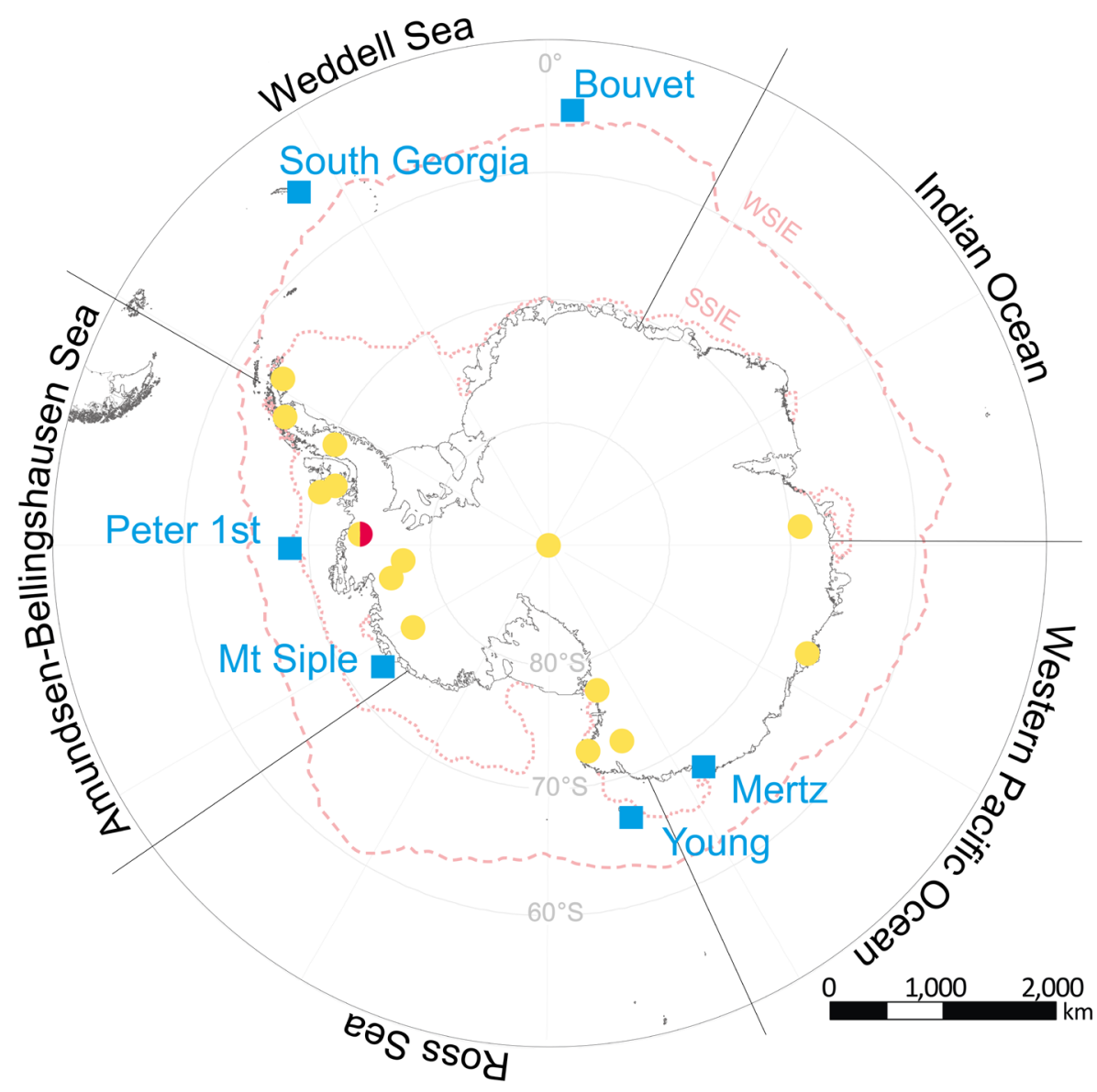

Figure 1: Locations of new sub-Antarctic ice cores (squares), alongside locations of cores previously used for reconstructing sea ice (yellow circles) and westerly winds (yellow/red circle) for the last 2000 years. Winter (WSIE) and summer sea-ice extent (SSIE; source: https://nsidc.org/data/g02135) are included for reference. 


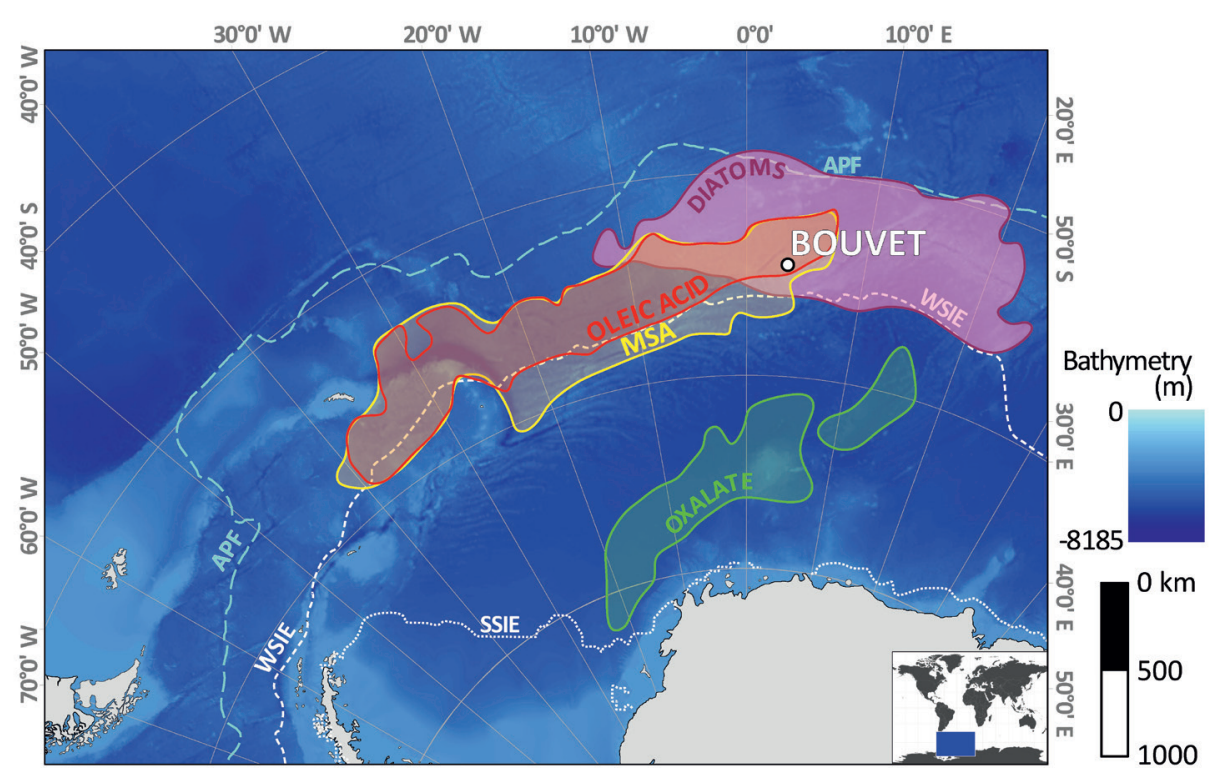

Figure 2: Location of Bouvet with geographical areas where core compound concentrations positively correlate with sea-ice concentration $(R=0.6, p<5 \%)$, and area where diatom concentration correlates with westerly winds $(R=0.6, p<5 \%)$. Also shown, how these correspond to winter (WSIE) and summer sea-ice extent (SSIE), and the Antarctic Polar Front (APF).

belt north of the Amundsen-Bellingshausen Sea, a positive (negative) correlation with latitudinal winds over the westerly wind belt (Antarctic coastal easterlies), and a positive correlation with offshore winds over the Amundsen Sea. These evidence the imprint of the Amundsen Sea low-pressure center driving the regional atmospheric circulation. Similarly, preliminary results from the Bouvet ice-core diatom record show a positive correlation $(R>0.7, p<5 \%)$ with wind strength over the westerly wind belt (Fig. 2). This is supported by a positive (negative) correlation with latitudinal winds over the westerly wind belt (Antarctic coastal easterlies) and a positive (negative) correlation with offshore (onshore) winds over the Weddell Sea. Both indicate that the presence of the Weddell low-pressure center drives the regional atmospheric circulation.

Preliminary results from these ice cores highlight their diatom records as valuable proxies of regional wind strength and atmospheric circulation in the sub-Antarctic region.

\section{Novel organic compounds as sea-ice markers}

Organic compounds are emitted from the surface ocean into the atmosphere by biochemical and physical processes. They are infrequently investigated in Antarctic icecore records due to low concentrations, a lack of current understanding, or both. One established marine organic proxy is methanesulfonic acid (MSA). MSA is an oxidation product of dimethyl sulfide, a chemical compound produced by phytoplankton blooms containing diatoms. Curran and Jones (2000) first proposed that MSA concentration may be interpreted as a sea-ice proxy under the following mechanisms: (1) Antarctic winters with a greater sea-ice extent also have a larger area of sea-ice decay during the following spring melt; (2) This bigger sea-ice break-up zone enhances phytoplankton blooming, and subsequently, production of MSA; (3) Atmospheric transport deposits MSA onto ice caps, incorporating the varying yearly concentrations into ice-core records.

Giorio et al. (2018) discussed a wealth of additional marine organic compounds that show potential for use as paleoclimate indicators. Analytical advances developed by King et al. (2019a), provided a method for analyzing up to 30 of these novel compounds simultaneously in ice samples. King et al. (2019b) subsequently applied these methods, alongside MSA analysis, to the first ever ice core drilled on the sub-Antarctic island Bouvet.

Results of the Bouvet ice-core analyses show a positive correlation ( $R=0.79 ; p<1 \%)$ between annual concentrations of MSA and oleic acid, the latter a fatty acid found in diatoms. Further investigation shows that a direct, positive correlation between annual oleic acid concentrations and each year's winter sea-ice concentration is found in a geographical area extending west of Bouvet Island, tracing the margin of maximum winter sea-ice extent (Fig. 2). Back-trajectory analysis (King et al. 2019b) ties the story together: westerly winds transport MSA and oleic acid, from spring blooming events in the sea-ice break-up zone to the west of Bouvet Island to the ice-core site, where they are deposited. Greater concentrations of MSA and oleic acid are emitted, transported, and deposited in years of greater maximum winter sea-ice extent.

The Bouvet ice-core analyses have also produced records of the marine organic compounds oxalate, formate, and acetate. Compound concentrations positively correlate with sea-ice concentration (King et al. 2019b). In contrast to oleic acid and MSA, the correlation exists for summer sea-ice concentration in a region south of Bouvet
Island (Fig. 2). A better understanding of the sources of these compounds is required to definitely define the mechanism behind this correlation.

Analysis of the Bouvet core shows great promise for the development of a suite of marine organic sea-ice markers in sub-Antarctic ice cores.

\section{Future directions}

Investigation of novel marine-sourced components in ice cores presents new climate proxies in the sub-Antarctic over the past few decades. Organic compound concentrations record variations in sea-ice concentration, and diatoms record westerly wind strength. Thus, diatoms and the fatty acid compounds they produce commonly link records of both emissions and transport of these components. Future work analyzing these components in further sub-Antarctic island cores will allow us to develop these archives throughout the sub-Antarctic, and extend records further back in time. Combining sea-ice proxy records from both marine-sediment and ice cores (Thomas et al. 2019) may provide sea-ice paleorecords of improved accuracy, longevity, and spatial coverage. All of these factors provide the critical context needed for improving future projections of change in the climate-influencing sub-Antarctic region.

\section{ACKNOWLEDGEMENTS}

Many thanks to Claire S. Allen for producing the Southern Ocean bathymetry map.

\section{AFFILIATIONS}

'British Antarctic Survey, Cambridge, UK ${ }^{2}$ Department of Earth Sciences, University of Cambridge, UK

\section{CONTACT}

Amy King: amyking@bas.ac.uk

\section{REFERENCES}

Allen CS et al. (2020) Geosciences 10: 87

Budgeon A et al. (2012) Antarct Sci 24: 527-535

Cipriano RJ, Blanchard D C (1981) J Geophys Res 86: 8085-8092

Curran MAJ, Jones B (2000) J Geophys Res Atmos 105: 451-459

Farmer D et al. (1993) Nature 361: 620-623

Giorio C et al. (2018) Quat Sci Rev 183: 1-22

Kellogg D, Kellogg T (2005) In: Castello J, Rogers S (Eds), Life in Ancient Ice. Princeton University Press, 69-93

King ACF et al. (2019a) Talanta 194: 233-242

King ACF et al. (2019b) Geophys Res Lett 46: 9930-9939

PAGES2k Consortium (2017) Sci Data 11: 1-33

Pike J et al. (2008) Mar Micropaleontol 67(3-4): 274-287

Tetzner D et al. (2021) Front Earth Sci 9: 617043

Thomas ER et al. (2019) Geosciences 9(12): 506

Thomas ER et al. (2020) Cryosphere Discuss,

doi:10.5194/tc-2020-110 